\title{
The Contribution of the Lesson Study to the Development of a Collaborative Framework for the Operation of the School: Results From a Pilot Implementation in Secondary Education in Greece
}

\author{
Eurydice-Maria Kanellopoulou ${ }^{1}$, Maria Darra ${ }^{1}$ \\ ${ }^{1}$ University of the Aegean, Rhodes, Greece \\ Correspondence: Eurydice-Maria Kanellopoulou, University of the Aegean, Rhodes, Greece.
}

Received: September 4, 2018

Accepted: September 25, 2018

Online Published: September 26, 2018

doi:10.11114/ijce.v1i2.3603

URL: https://doi.org/10.11114/ijce.v1i2.3603

\begin{abstract}
The main purpose of the present study is to investigate the contribution of the lesson study to the formation of a collaborative framework for the operation of the school unit. Qualitative research was conducted from February 12 to April 1, 2016, in the second grade secondary school of Attica, with a total of 31 students and four teachers. The results of the survey show that the lesson study cultivates and strengthens the collaborative climate among the participating teachers, which has positive effects not only on their own but also on their students. In particular, research has highlighted the ways in which the lesson study builds co-operation among teachers, as well as the benefits of this collaboration for participating teachers and pupils. Also, the importance of collaboration and the development of collaborative culture, in the context of a fruitful and constructive dialogue, have emerged as the strengths of the lesson study.
\end{abstract}

Keywords: collaborative culture, collaborative learning, lesson study, secondary education, students' performance

\section{Introduction}

Nowadays, searching for ways to improve the effectiveness of the school unit is a field of systematic research by Greek and foreign researchers. Many researchers believe that teacher collaboration in schools contributes decisively to its effectiveness and continuous improvement of its educational work (Athanasoula-Reppa, 1999; Raymond, Butt, \& Townsend, 1993). In building this collaborative framework, a new way of teaching, the lesson study, can play an important role (Lewis \& Hurd, 2011).

From the review of the relevant research on the contribution of the lesson study to the formation of a collaborative framework of the school, certain findings are presented, which are summarized below.

In the international literature there are researches that have focused on exploring the contribution of the lesson study to the professional development of teachers and improving pupils' learning (Archer, Pope, Onion, \& Wake, 2013; Meyer, 2005; Van Sickle, 2011) and highlights its significant benefits in the above areas. Also, a related research (Thompson, 2015) has found that the lesson study is a valuable tool for the professional development of both young and inexperienced teachers as well as the oldest and most experienced teachers.

In addition, Van Sickle (2011) conducted a survey of 59 high school teachers in California, USA in order to explore the scope of the lesson study and how this affects their perceptions of effective teaching and learning, found that the lesson study impacted greatly on their teaching, improving their ability to match their teaching strategies in relation to learners' learning needs. Research findings have also shown that the implementation of the lesson study increases teachers' self-confidence and has immediate benefits in learning learners through the collaboration that develops among teachers.

Meyer (2005) also researched 13 secondary school mathematicians in three schools with 310, 437 and 461 students, respectively, in Texas, USA, to examine the results of the lesson study in their teaching and the performance of their students. The results of the survey revealed that the lesson study positively influences teachers' teaching strategies in the areas of reflection and encouragement of collaborative learning. Also, the results showed that in two of the three schools performance of students in mathematics improved.

In addition, Archer et al. (2013) investigated the perceptions of 50 graduate students of mathematics at Manchester 
University in five different schools. From the results of the research, it came to the conclusion that lesson study contributes significantly to improving the teaching of new and inexperienced teachers. It has also been established that cooperation among teachers, as well as their voluntary and equal participation, are considered to be prerequisites for the success of the lesson study (Collins, 2017; Mynott, 2017; Sirotic, 2015).

Lenski, Caskey and Anfara (2009) report that in her research Fernandez (2002), in addition to the advantages of the lesson study, found several obstacles to the implementation of this method. The lack of time for co-operation with colleagues, the fear of exposure to team members and the critical analysis of collegiate teaching practices are difficulties in the implementation of the lesson study.

Also, from the review of the relevant researches on the lesson study in the Greek educational reality, it appears that only two surveys have been carried out, one in the primary education (Panoutsos, 2015) and one in the higher education (Rekalidou, Karadimitriou, \& Moumoulidou, 2013), while no research has been carried out which to explore its contribution to the development of a collaborative framework for the operation of the school in secondary education. In particular, Panoutsos (2015), in his qualitative research in primary education, took advantage of the didactic approach of the lesson study on the teaching of the subject of Mathematics of the fifth elementary school with the participation of 7 teachers, 3 researchers and 21 students and found the value of cooperation of teachers to improve the efficiency of teaching. At the same time, in the higher education, Rekalidou et al. (2013) researched 129 graduate students of the preschool education department of the Democritus University of Thrace in order to investigate the contribution of the lesson study in their practical training. The results of this research have highlighted the development of collaboration as well as the familiarization of students with the observation, reflection and feedback processes as important benefits of the lesson study.

It follows from the above: a) that through the implementation of the lesson study in the classroom the cooperation between the participating teachers is achieved and $b$ ) the lack of experimental research to evaluate the effectiveness of the lesson study in the development of a collaborative framework of the school's operation in the Greek secondary education. The lack of this is intended to cover this research.

\section{Lesson Study and Formation of a Collaborative Framework of the School's Operation: A Theoretical Approach}

\subsection{Lesson Study}

The lesson study is a process of improving teaching and learning, not only for students but also for teachers, which originally appeared in Japan (Rekalidou, 2012).

Within this framework, the participating teachers collaborate collectively for their professional development, creating learning communities through the design of a research lesson. Teaching and observation serves to collect data on student learning. The use of these data for feedback and redesign of teaching contributes decisively to the improvement of teachers (Stepanek, Appel, Leong, Mangan, \& Mitchell, 2007).

For the implementation of the lesson study, teachers devote 10-15 hours in 3-4 weeks (Fernandez, 2002). The lesson study process, as shown in the diagram below (Stepanek et al., 2007), includes the following phases:

I. Setting goals

II. Planning the research lesson

III. Teaching, observing and data collecting of the research lesson

IV. Evaluation - feedback and re-teaching

V. Reflection - formulation and sharing final results 
Process of Lesson Studv

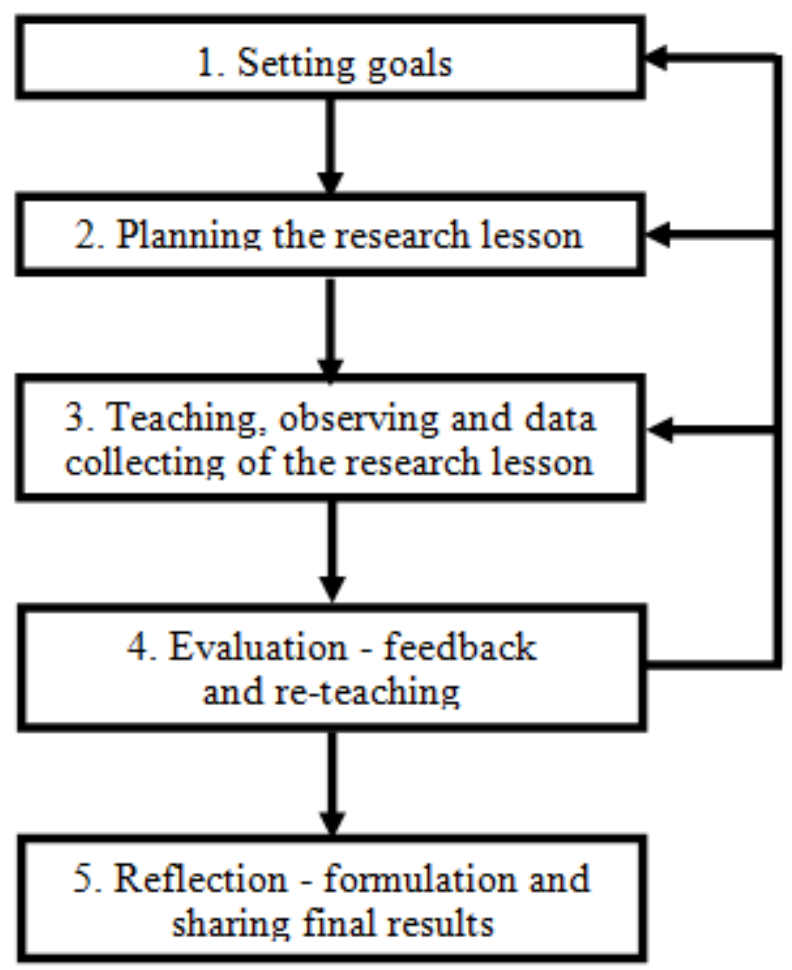

Figure 1. Phases of the lesson study. Adaptation by Stepanek et al. 2007

\section{Setting goals}

In the first phase of the lesson study, teachers work together to form a small group of 3-6 people (Cerbin \& Kopp, 2011) to look at the goals that their pupils aspire to. By studying the curriculum, they detect gaps between these future goals and the existing reality. They are looking for an important subject for students that is of interest or learning difficulty or a new module that has recently been added to the curriculum. They explore through brainstorming, in the context of a fruitful dialogue, strategies and teaching methods that will direct their students to gain knowledge of the subject. Teachers justifying their chosen didactic approaches, set the foundations for a proper design of learning objectives (Lewis \& Hurd, 2011; Rekalidou, 2012).

\section{Planning the research lesson}

Teachers choose a module from the curriculum that is directly related to this subject, and collaboratively design a research lesson in detail. This course will accomplish the aims, learning and development of pupils and, in particular, not what they will learn, but rather how they will learn (Cerbin \& Kopp, 2006). At this stage, teachers spend enough time to organize the teaching together. They form the learning pathway to follow, predict the expected questions from their students (Verhoef \& Tall, 2011) and prepare a data collection plan. During these meetings, observations and suggestions for improvement of the teaching plan are made. At the end of this phase, a written analytical teaching plan emerges, which the group is asked to implement in the classroom (Lewis \& Hurd, 2011; Rekalidou, 2012).

III. Teaching, observing and data collecting of the research lesson

The research lesson is conducted, with one member of the group teaching and the rest observing and collecting data on the teaching and learning of the pupils (Shaun, 2014). This collection can be implemented by various means. The recording of notes and observations, as well as the oral and written answers of the students are used in the evaluation-feedback (Rekalidou, 2012; Stepanek et al., 2007).

IV. Evaluation-feedback and re-teaching

In the context of the evaluation, teachers analyze in depth the data collected during the course. The purpose of the evaluation is not to critique the way the teacher teaches the lesson. Evaluation-feedback aims to extract valuable conclusions on the design of the lesson and unity and, therefore, to improve the learning of pupils and teachers. Applying improvements can mark the end of the phase of the lesson study process or redesigning the same lesson or conducting subsequent lesson studies with a different subject (Easton, 2009). If re-design is appropriate in the context of 
evaluation-feedback, re-design is implemented in another part of the same class by another teacher of the same group (Rekalidou, 2012), due to incorrect oral or written answers to the students'.

\section{Reflection-formulation and sharing final results}

The process of the lesson study ends with the reflection, the formulation, the final conclusions and their publication (Hiebert, Gallimore, \& Stigler, 2002). Reflection reinforces the collectivity of teachers who review the research lesson (Polemi-Todoulou, 2010). The written formulation of the conclusions is carried out through interactive discussion and joint analysis of the data and results of the research lesson. These conclusions can be used and exploited by other groups of teachers interested in implementing the lesson study.

\subsection{Cooperative Framework of the Operation of Schools and the Lesson Study Contribution to Its Construction}

The fruitful interaction of all members of the school community builds the cooperative framework for the operation of schools. This cooperative culture is shaped by the particular characteristics of the school's indoor and outdoor environment (Papakonstantinou, 2008).

In order to shape the school culture, communication and interpersonal relationships that develop between the teachers of an educational unit play a catalytic role. In particular, the cultivation of collaborative culture is based on mutual respect, mutual appreciation (Syvaka \& Ginoudi, 2014), support and encouragement among members of the school community (Raymond et al., 1993). It also presupposes a sincere willingness to communicate and exchange views on the achievement of their common goals (Koula, 2011). It is also founded on the application of innovative methods and techniques of teaching for the professional development of teachers (Clark, 1993).

The collaborative culture is formed into teachers' working groups. Within them, teachers due to different perceptions and goals (Koula, 2011) may strongly disagree and lead to conflicts. But in the context of collaborative culture, conflicts are constructively dealt with (Bouradas, 2001), they are identified in terms of ideas rather than individuals, and they result in the creative synthesis of opinions (Syvaka \& Ginoudi, 2014).

In schools where there is no culture of cooperation, teachers isolated in classroom loneliness are content with the formal teaching of the lesson and avoid participating in group actions (Hargreaves, 1993). They do not take creative and innovative initiatives, considering they are not their own duties. Their typical presence in the operation of the school suggests their individualistic mindset and indifference to their professional development (Mavrogiorgos, 2008).

In order to gradually change this negative climate, teachers can resort to artificial fellowship, which acts as a substitute for authentic co-operation, which requires much longer to achieve (Hargeaves, 1993). Artificial collegiality may also be imposed by the director to ensure the smooth functioning of the school by encouraging communication between teachers. The latter, over time, may develop a true culture of collaboration and collectivity.

The development of collaborative culture makes a decisive contribution to improving students' performance (Oliva, 1993), teacher performance, and school efficiency (Chatzipanagiotou, 2008).

Students, observing cooperation between teachers and the director, are familiar with the exchange of ideas and fruitful dialogue. They learn to respect the different views of their classmates, to work within groups and to take collective action to achieve common goals (Yakoumi \& Theofilidis, 2012).

Teachers, through collaborative culture and teamwork, can cope with the stress of everyday life more effectively and creatively. They can jointly elaborate course plans and apply different teaching techniques and methods to improve them (Raymond et al., 1993).

The lesson study develops cooperation and communication among teachers and strengthens friendly interpersonal relationships, contributing to the enhancement of collaborative culture. In particular, with this teaching method, teachers' participation and fruitful exchange of ideas are fostered within the working groups (Kambouridis, 2002). At workshop meetings of the lesson study, honest relationships of mutual respect and appreciation are developed. Through the lesson study and the teaching of the research lesson, teachers do not hesitate to expose and collaborate with their colleagues (Thiessen, 1993). Disengagement from classroom isolation (Hargreaves, 1993) contributes to collaboration and support between them and is a model for students. Teachers work together, through the lesson study, to achieve their professional development with the valuable help of the director. This shared vision strengthens even more the collaborative culture of the school unit (Syvaka \& Ginoudi, 2014).

Also, the lesson study, triggering the active cooperation and participation of teachers, may be the starting point for corresponding behavior in school management issues. The honest and friendly relationships that are developed in the lesson study, consolidate dialogue and fruitful exchange of views. This constructive interaction can be extended to the issues of operation and administration of the school. The formation of working groups for conducting the lesson study and the assignment of the responsibilities by the director to the teachers leads to the acquisition of experience in 
collective and democratic activities. In this way, the authoritarian style of administration is weakened and the feeling of participation of teachers in the school administration is strengthened. The lesson study, with its innovations in teaching practice, reduces resistance to change and favors the transformation of the conservative mentality of director and teachers. It is an important opportunity for teacher training in the classroom and for upgrading the educational work produced, which determines the effectiveness of the school unit.

\subsection{Critical Evaluation of Existing Literature}

From the above-mentioned theoretical considerations, it is perceived that the identification of practices and factors / parameters with the greatest positive influence on the formation of collaborative school culture and consequently on the effectiveness of teaching and the school success of students is one of the important issues.

Additionally, on the basis of the above, and given that:

a. the lesson study could be described as a series of processes through which teachers systematically examine their teaching methods, their teaching contents, their programs and the strategies they apply to the classroom,

b. the purpose of the lesson study is to improve classroom teaching and learning and is based on the logic of co-operation, mutual evaluation and feedback between members of a group of teachers who in the classroom have the role of a researcher who they use for their professional promotion and the benefit of their students,

c. the design of teaching as a criterion for its effectiveness is very important,

d. In the context of the lesson study implementation, teachers' cooperation is enhanced in the design of teaching, and pupil learning is improved, and

e. there is a lack of corresponding research work on the use of lesson study in Greek secondary education; the investigation of the contribution of collaborative design of teaching in the context of the application of the approach to the lesson study in the development of a collaborative framework of the operation of the school is of particular interest. This is the aim of this paper.

The data collected in the context of this paper can provide answers to questions about the contribution and evaluation of the effectiveness of modern approaches to improving the quality of teaching, such as the approach of the lesson study, the development of cooperation between teachers, an issue of particular interest that is expected to contribute to the broadening of knowledge in the field of improving the effectiveness and quality of the educational work provided in schools and consequently the professional development of teachers.

\section{Research Methodology}

The present work, which is part of a wider research effort, followed a mixed methodological design for triangulation purposes.

In this qualitative survey, sample selection was deliberate and not accidental, as is done in quantitative surveys, which aim at generalizing their results. On the contrary, qualitative surveys aim at a more thorough and detailed examination of a subject (Creswell, 2011). In this research work, a selection criterion was the participation of teachers and pupils who can contribute to understanding the impact of the lesson study on improving the functioning of the school. This qualitative research requires direct researcher access to the environment of a school unit. The choice of the school in which the researcher works has made a decisive contribution to its realization.

The research was conducted in the second grade of general lyceum of Eastern Attica from February 12 to April 1, 2016, in the subject of Literature with the permission of the relevant school counselors and the director of the school unit. The director and, initially, all the school's scholars (4) participated, one then left. The two parts of the secondary school were also involved, the first consisting of sixteen (16) students as the experimental group and the second of fifteen (15) as a control group. Teachers' meetings were held on a regular weekly basis within the school hours, with few exceptions, and their participation was voluntary.

Data-gathering tools used transcripts of participant teachers in the lesson study and teaching (traditional and research lessons). Also, data were calendars that were complied with at the time of the lesson study by the facilitator and the group recorder, as well as the protocols for design, observation, reflection and revision of the research lesson. Sources were also the work of the students, as well as the questionnaires completed by the teachers. The questionnaires also generate quantitative data, which is used to enhance the in-depth analysis of quality data. The existence of the above-mentioned different data sources contributed through triangulation to the validation of research results, which give it credibility and validity (Robson, 2010).

\section{Purpose and Research Questions}

The main aim of this paper is to investigate the contribution of the lesson study approach to the development of a 
collaborative framework for the operation of the school. In particular, the paper aims to explore the perceptions and attitudes of teachers regarding: a. the ways in which the lesson study cultivates the collaborative climate among the teachers of a school; $b$. the benefits of teachers' collaboration for teachers and students; and $c$. the strengths of the lesson study.

The individual research questions that the research will attempt to answer are:

1st: What are the perceptions of teachers regarding the ways in which the lesson study cultivates the collaborative climate among the teachers of a school unit?

2nd: What are the benefits of teachers 'and pupils' cooperation?

3rd: What are the strengths of the lesson study?

\subsection{Collection of Research Data}

\section{The meetings and the teachings}

The meetings and the teachings which conducted during the lesson study were recorded for the fullest collection of data and the best documentation of the research.

At the introductory meeting, the participating teachers were thoroughly informed about the content and phases of the lesson study. As a matter of course, the lesson of Modern Greek Literature was unanimously chosen, which presents some peculiarities and is the only lesson that teaches all the school's scholars. It was also agreed to teach a particular poem and his traditional teaching to be conducted before the start of the lesson study so that the teacher is not influenced by the implementation of the new way of teaching. An indicative timetable for the implementation of traditional teaching and subsequent meetings was established. The six subsequent meetings, following traditional teaching, were devoted to the detailed design of the research lesson. After his teaching, the last meeting provided important data for evaluation-feedback and reflection of the research lesson.

\section{Meeting calendars}

Meeting calendars were another tool of this research, as important elements of the lesson study meetings were recorded at the end of the lecture. These figures were particularly useful, especially when a reasonable time span between the meetings and there was a risk of being forgotten and ignored. In the present study, two types of calendars were drawn from Stepanek et al. (2007).

In the first type, the calendar was completed by one member of the group and the second type by the facilitator. These two team members changed at each meeting. The two calendars had common fields related to the objectives and main points of the meeting and were differentiated in the other fields.

In particular, in the member's calendar were recorded data on the content of the meeting, teaching, pupil learning, and the short and long-term goals of the group. Steps were also taken to plan the next meeting and define its content.

In the corresponding calendar, the facilitator initially mentioned his actions, which contributed to the effective participation of the team members. Then he noted any problems that arose at the meeting, and how to deal with them. He mentioned the degree of participation of all members of the group, as well as the possible strengthening of their cooperation.

\section{Protocol design of the research lesson}

The design protocol for the research lesson used in this research is from Stepanek et al. (2007) and took place in four stages.

The first one identified the research topic according to the students' cognitive level, their educational needs, the teachers' learning needs, and the gaps or shortcomings found in the curriculum. In the second stage the module and the research lesson were selected. The lesson was chosen according to the student's knowledge and needs.

In the third stage, the objectives of the course were identified. At the final stage, the team of the lesson study jointly developed a detailed plan of the research lesson. With this plan, teachers using pre-existing knowledge of students anticipated possible questions or difficulties in understanding the course and designed activities for student assessment.

IV. Protocol on revision of the research lesson

Protocol on revision of the research lesson was necessary for the completeness of the research and was applied by Stepanek et al. (2007) and implemented in four steps.

In the first step, the collection and critical data, the participating teachers worked out the tools of observation and reflection of the research lesson. They also took note of their notes, as well as the answers of the students, both oral and written. In the data analysis, they determined the extent to which the learning objectives were achieved and the teaching 
points that helped or made it difficult for students to achieve their cognitive goals. In identifying the necessary changes, they jointly decided which parts of the teaching were successful and which need changes and improvement interventions. In the final step of reviewing the lesson plan, teachers have developed a revised and detailed plan for teaching the research lesson according to their observations.

V. Teacher's questionnaire

In the present study, a questionnaire from Stepanek et al. (2007) was distributed to the participating teachers during the reflection phase which was partially amended to cover its needs. This questionnaire included, in particular, closed and open-ended questions.

For the purposes of this study, which is part of a broader research, only the participating teachers' answers to the open-ended questions were used. In particular, the data from the participating teachers' answers to the five open-ended questions are presented where teachers were asked to identify the strengths and weaknesses of the lesson study, to suggest ways to improve it, and to express their views on the contribution of the lesson study to cultivating collaborative climate and improving the learning process.

\section{Results of the Survey}

Recorded meetings and teachings, traditional and research lesson were transcribed in digital form as text files. Subsequently, these records were analyzed and combined with other research data sources were categorized into fields that are directly related to research questions. The results and main findings of the research are as follows:

Ways of forming a collaborative framework between teachers-

Benefits of teachers' collaboration for teachers and students

At the meetings of the participating teachers in the framework of the lesson study, as well as in the calendars of the facilitator and the recorder of the group, the cooperative climate that developed during its conduct is highlighted.

As shown in the following quotes of the first meeting, we observe the creative cooperation of teachers in the initial briefing about the design of the lesson study and its benefits for students and teachers:

Professor B: For example, to make a poem by Karyotakis. Because we are in the middle of the year. It's a typical text of the 20th century. I had to propose Karyotakis' poem: "We are something ..." that exists in the school book of the $2^{\text {nd }}$ lyceum. It has some specific topics that would be quite indicative for our students to learn and discuss.

Professor A: Indeed. I do not know. You colleague. The other colleague?

Professor C: We agree.

Also, fruitful collaboration is shown by the positive treatment of Professor B's proposal by the other members of the group:

Professor A: So, it's an interesting poem. I agree, I have no objection. So can we deal with this?

Professor D: Probably we can.

In addition, cooperation is reflected in the following quote of the facilitator's calendar:

Communicating the benefits of the lesson study for pupils and teachers has motivated the latter more to participate voluntarily and actively in its implementation.

The group's recorder shares the same view:

The first meeting created high expectations for team members.

At the second meeting, the withdrawal of a professor $(\mathrm{C})$, due to his inability to work with the other members of the group, did not affect the cooperation of the rest of the group:

Professor A: That is, unity will be the poetry of the interwar period, so.

Professor B: The Poetry of the Interwar. This is what I personally suggest. What is your opinion;

Professor A: Okay. We agree.

Professor D: Okay.

The facilitator's calendar is noted characteristically:

Encouraging fruitful exchange of views through dialogue and shaping a collaborative climate in the group. Also, the total lack of participation by a team member who left, did not lead to the splitting of the team, which continued its work.

The recorder's calendar of the group also states that: 
The withdrawal of a colleague from the group, due to a lack of cooperation with the other members, did not affect the co-operative climate.

In the third meeting established the co-operative climate, as shown in the following quote:

Professor A: Fine. Now we have to design an activity for the students that they will implement in groups and they will use New Technologies. What do you suggest; What kind of exercise do we put?

Professor B: For example, we could ask them to create a power point with the author's biographies and other information about him.

Professor D: We could still make use of the melody of the poem.

Professor B: Right. This is a good idea. Because the poem has become a song.

The facilitator's calendar of the group records that:

Through the fruitful dialogue and the cultivation of a mutual respect and mutual understanding, I urged them all to anticipate potential student questions and to propose questions and exercises for the research lesson. The team at this stage did not face any problems. All members of the group participated equally, actively, in a climate of co-operation, mutual respect and mutual understanding. They participated more actively and with greater interest. There was enthusiasm in the team and there were no signs of fatigue or indifference.

The recorder's calendar states that:

The group's work continued normally according to the original design and was not affected by the withdrawal of a member in the previous meeting.

In the fourth meeting, as shown in the quote, different opinions are treated in a synthetic and cooperative way:

Professor B: In order to trigger students' interest so as to get in the mood of the poem usually three minutes are required.

Professor A: Within three minutes, that is, to show the drawing and answer all the questions that my colleague had said before? Is it a bit?

Professor B: Five minutes.

Professor A: Five minutes to trigger students' interest?

Professor B: Okay. Yes, five minutes. Necessarily above no.

The facilitator's calendar highlights:

Developing the right climate for free expression of views and suggestions for the detailed design of the teaching plan. The roles of each member of the group were proposed and agreed and no direct assignment was made. No problems, no frictions or conflicts arise. As in previous meetings, all members of the group participated actively and had creative interventions. There was a keen interest and willingness to contribute to team effort. The team spirit among the members of the group was established with their equal participation.

The recorder's calendar shows that:

The team works intensely to achieve its goals in a friendly and enjoyable climate.

At the fifth meeting, as shown in the following quote, teachers improve the analytical teaching plan in a climate of fruitful collaboration and constructive dialogue:

Professor D: We ask students to highlight this information.

Professor A: Yes. Then the poem is read by the teacher. We ask them what their impressions or concerns are, and we mark on the blackboard answers that are useful to us, for example, pictures, melancholy mood,

Professor B: We will then give them a little time to re-read the text themselves.

Professor A: Right. Then we have to ask them if they have unknown words. Can we predict which words are probably unknown to our students? Can we mention a few?

Professor D: Possibly the words: sonnet, antennas, diffuse, chaos, echoes.

Professor B: First we will ask our classmates if they know the word, then we will try to help them somehow find their meaning by saying let's say how

Professor A: Etymology perhaps, yes.

Professor B: And if they can not answer then we will give the answer. 
Professor A: We agree. Okay.

The facilitator in his calendar notes that:

Participation of all members of the group were promoted, who were able to express their views in a spirit of cooperation and mutual respect. No particular problem was observed. The members participated with enthusiasm and sincere interest in the success of the lesson study. Their interest has increased as the teaching of the research lesson approaches, in which the whole project will be evaluated. Expectation for the realization of the research lesson.

The recorder in his calendar says:

The team looks forward to the teaching of the research lesson in order to find out in practice the positive elements of the lesson study.

At the sixth brief meeting, teachers discuss the latest details just before teaching the research lesson, in a climate of loyal cooperation.

Professor A: Fine. And you colleague observe the course of achieving the goals from the other two groups third and fourth, and the infrastructure.

Professor D: Fine.

Professor A: We take into account the instructions for observing the research lesson. We had told them the previous time.

Professor B: Yes. Correctly.

Professor D: Okay.

Professor A: Fine. Have a question, something else to ask about the process.

Professor D: No.

Professor A: You have the tool of the lesson's observation.

Professor B: We have been prepared for this.

Professor D: Okay. We are ready for the lesson

In the seventh meeting, in the process of evaluation and reflection of the research lesson, the participating teachers emphasize the importance of their cooperation for the success of the project, as shown in the following quote:

Professor B: We had excellent communication.

Professor A: And I think we worked very well.

Professor B: And productive.

Professor A: Right.

Professor D: Collaboration between us both before and during the teaching.

Professor B: Sure.

Professor D: We all co-developed a common understanding of lesson study's teaching.

Professor B: Because we all participated in the formation.

The facilitator's calendar is described:

The rotation of roles in our meetings, which fostered a positive climate of communication and respect for the different view. There was no particular problem. All members of the group participated with feelings of satisfaction from meeting the objectives of the lesson study. Continuous flawless collaboration and willingness of team members to complement each other with no intention of conceit or demonstration of knowledge. The full satisfaction of the members from their participation in the lesson study.

The recorder's calendar records the lesson study as:

A very positive experience for all of us, because the friendly relations between us developed more and we became acquainted with the development and cultivation of a collaborative climate.

Strengths of the lesson study

In addition to the meetings and calendars, also in the open-ended question of the teachers' questionnaire:

What do you think are the strengths of the lesson study?

among others, teachers emphasized the importance of working together in their esponses. 
Still, to the question:

What is the contribution of the lesson study to building a collaborative culture among the teachers of a school unit? reported characteristically that:

It is important because teachers learn to cooperate, develop friendly relationships and can also collaborate outside of the lesson study on school unit issues.

As well as:

Positive if teachers are often available for this and there is a consensus.

The total of data on teacher cooperation is presented in summary form according to the Atlas program, with the following tree plan:

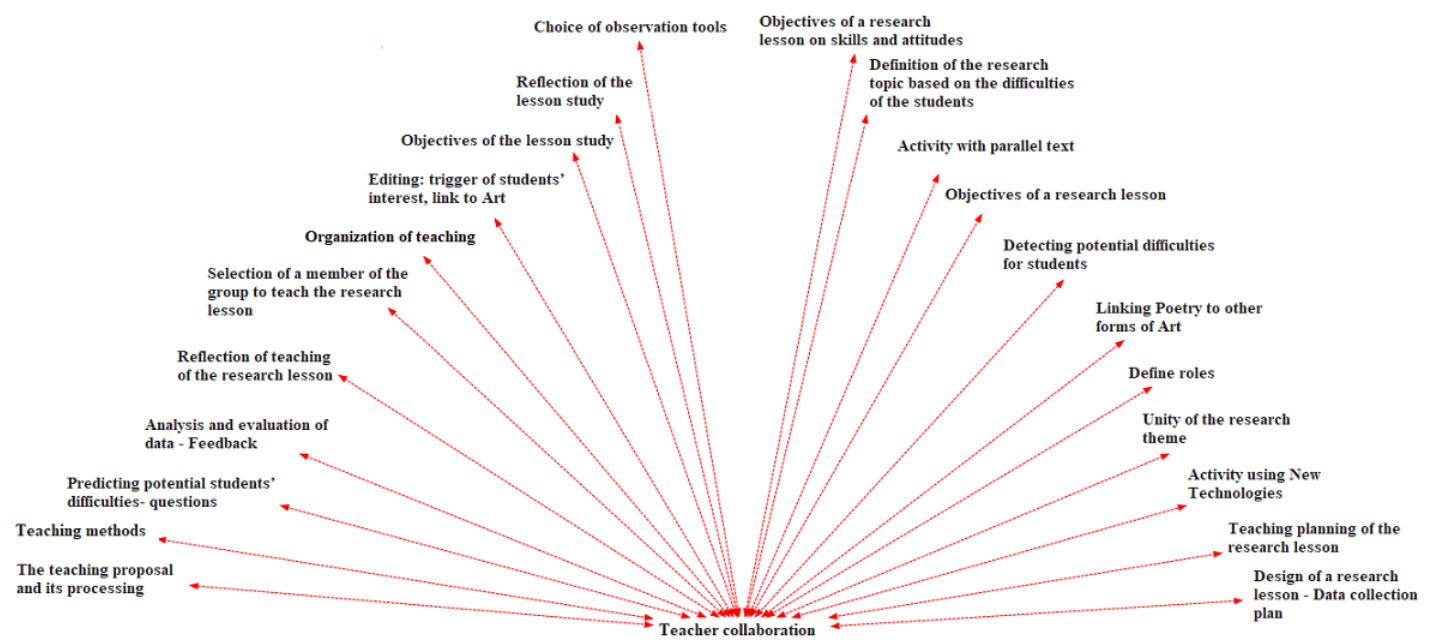

Figure 2. Tree diagram illustrating teacher references regarding their collaboration during their meetings

\section{Discussion}

From the overall view of the individual findings, there are specific findings regarding the contribution of the collaborative design of teaching in the context of the implementation of the lesson study approach to the development of a collaborative framework for the operation of the school, which are described in more detail below.

According to the results of the survey, the lesson study cultivates the collaborative climate among the teachers of a school unit, which contributes positively to its operation. This is because, in its context, the participating teachers cooperate and exchange views through a fruitful and constructive dialogue. Dialogue strengthens two-way communication between team members and consolidates their conviction that they share common values, goals and visions for their school. This finding is consistent with the views of the researchers as reflected in the Greek and international literature (Koula, 2011; Kruse \& Lewis, 1997). With this result of our research agree the findings of relevant researches (Oliva, 1993; Rock \& Wilson, 2005; Stepanek et al., 2007), according to which the lesson study contributes to the widening of the cooperation between of teachers and the development of skills resulting from cooperation.

This result is also consistent with the literature (Car \& Kemmis, 1997), according to which teachers who work in a communicative and reflective context interpret their practice thoughtfully and the practice of other participants and are in constant readiness to redefine their goals.

In addition, this result means that the teacher through participation in a group of colleagues can better achieve the goal of improving the effectiveness of teaching if he /she relies on the reflection and feedback he/ she can get from his colleagues' team, which provides a supportive environment in which everyone feels that they are learning and constantly improving and evolving professionally (Barkley \& Cohn, 1999).

In particular, the survey found that all of the participating teachers recognized cooperation as a basic prerequisite for the success of their collective effort. In all their meetings, teachers paid particular attention to their good cooperation. This perception of teachers was also reflected in the open-ended questions in the questionnaire. In the question about the advantages of the lesson study, all teachers found the importance of cooperation. In the question about the contribution of the lesson study to building a collaborative culture, teachers responded that it is very important. However, a teacher, perhaps influenced by the withdrawal of a member of the group, stressed the prerequisite of sincere willingness to 
participate in the lesson study. The voluntary and equal participation of teachers, as noted by them throughout the meetings, is in line with the Lewis and Hurd (2011) view that they consider to be an important factor in the success of the lesson study. Also, from these findings, which are in line with the relevant literature (Rekalidou, 2012; Rock \& Wilson, 2005), it appears that improving classroom teaching and learning is achieved when it is based on the logic of co-operation, interevaluation and feedback between teachers and, in particular, when teachers during the educational process have the role of a researcher who they use for their professional promotion and for the benefit of their pupils (Coenders \& Verhoef, 2018). In addition, these findings highlight the contribution of the lesson study to building positive interpersonal relationships between teachers and their motivation to continuously improve classroom teaching (Lewis, Perry, \& Hurd, 2004).

\section{Conclusions}

Firstly, the lesson study, according to all the participating teachers, contributed significantly to the building of the cooperation between them and to the proper functioning of the school unit. The cooperation and the fruitful exchange of views, ideas, arguments and teaching techniques, according to the opinions of all teachers, broadened their knowledge and promoted their professional development. This development was directed by themselves, with their voluntary participation and worked as a form of training within the school unit.

However, an issue that arose during the survey was the withdrawal of a member of the team, which could endanger even frustrating the implementation of the lesson study. Consequently, the lack of incentives for the voluntary participation of teachers in the lesson study is a significant inhibitory factor which was found in the conduct of this research.

In spite of the positive results from the use of the lesson study in the development of a collaborative framework for the operation of the school, there are some limitations that should be mentioned. The sample of the survey, 31 students, was relatively small. Using a larger sample would increase the credibility of the survey. There were time constraints on the implementation of the research program, which did not allow for longer duration. Finally, as in each survey, participants, and in this case students, may not have been completely honest in their responses to their impressions, linking the conduct of research to the exam process.

From the work constraints, the proposals for further research, which could focus on the following axes, arise. This research was conducted only in the teaching of Literature in students of the 2nd class of a lyceum. Future studies could examine the effectiveness of lesson study in teaching and other subject matter in pupils of lower and / or older classes. Finally, future surveys could use a combination of quantitative and qualitative approaches and, in particular, conduct personal interviews with students, teachers, and education executives.

The next phase could be to set up a more extensive program of interventions, which, over a longer period, will also include teaching in more subjects. The implementation of such a program in a larger group of students and with the participation of a larger number of teachers and the comparative study of the data, should provide a more complete picture of the effectiveness of the lesson study with regard to other parameters of the didactic-learning process, such as exploring its contribution to mobilizing students, shaping students' positive attitudes towards school and learning, as a result of its implementation, and others.

\section{References}

Archer, R., Pope, S., Onion, A., \& Wake, G. (2013). Working group report: lesson study in research and CPD in mathematics education. Available at: http://www.bsrlm.org.uk/lps/ip33-2/BSRLM-IP-33-2-C

Athanasoula-Reppa, A. (1999). Communication with the educational organization. In: A. Athanasoula-Reppa, S-S. Antonopoulou, S. Katsoulakis, \& G. Mavrogiorgos. Management of Educational Units: Human Resources Management. v.2, 137-185. Patras: OR.

Barkley, S., \& Cohn, R. (1999). Professional growth plans offer alternative to teacher checklists. The School Administrator Web Edition. Retrieved from: www.aasa.org.

Bouradas, D. (2001). Management: Theoretical Background, Modern Practices. Athens: Benou Publications.

Car, W., \& Kemmis, S. (1997). For a Critical Educational Theory: Education, Knowledge and Action Research (A. Lambraki-Paganou, E. Blinga, and K. Rodiadou-Albani). Athens: Code.

Cerbin, B., \& Kopp, B. (2006). Lesson study as a model for building pedagogical Knowledge and improving teaching. International Journal of Teaching and Learning in Higher Education, 18(3), 250-257.

Cerbin, B., \& Kopp, B. (2011). Lesson study project overview. Retrieved from http://www.uwlax.edu/sotl//sp/overview.htm 
Chatzipanagiotou, P. (2008). The role of culture in the efficiency of the school organization. In: Educational Guide: Intercultural Education and Education, 213-230. Thessaloniki.

Clark, C. (1993). Teachers as designers in self-guided professional development. In: Hargreaves, A., \& Fullan, M. The evolution of teachers. Transl.: P. Chatzipantelis. Athens: Pataki.

Coenders, F., \& Verhoef, N. (2018). Lesson study: professional development (PD) for beginning and experienced teachers. Professional Development in Education. https://doi.org/10.1080/19415257.2018.1430050

Collins, T. (2017). Lesson study as professional development within secondary physics teacher professional learning communities. (Doctoral Dissertation). University of Alabama, USA. Retrieved from: https://ir.ua.edu/bitstream/handle/123456789/3219/file_1.pdf?sequence=1\&isAllowed=y

Creswell, J. (2011). Research in education. Design, Conduct and Evaluation of Quantitative and Qualitative Research. Transl.: N. Kouvarakou. Edited by: C. Tsorbatzoudis. Athens: Ion.

Easton, L. (2009). An Introduction to Lesson Study. Florida and the Islands Regional Comprehensive Center. Day One. November \& December, 1-35.

Fernandez, C. (2002). Learning from Japanese approaches to professional development: the case of lesson study. Journal of Teachers Education, 53(5), 393-405. https://doi.org/10.1177/002248702237394

Hargreaves, A. (1993). Teachers' attitudes: a goal of change. In: Hargreaves, A., \& Fullan, M. The evolution of teachers. Transl.: P. Chatzipantelis. Athens: Pataki.

Hiebert, J., Gallimore, R., \& Stigler, J. (2002). A Knowledge base for the teaching profession: What would it look like and how can we get one? Educational Researcher, 31(5), 3-15. https://doi.org/10.3102/0013189X031005003

Kambouridis, G. (2002). Organization and Administration of School Units. Athens: Klidarithmos.

Koula, B. (2011). Interpersonal Relations of School Unit and Teacher Directors: Contributing to the effective functioning of the school unit. Doctoral Thesis. Thessaloniki, Aristotle University. https://doi.org/10.12681/eadd/25165

Kruse, S. D., \& Lewis, K. S. (1997). Teacher Teaming in Middle Schools: Dilemmas for a Schoolwide Community. Educational Administration Quarterly, 33(3), 261-289. https://doi.org/10.1177/0013161X97033003002

Lenski, S., Caskey, M., \& Anfara, V. (2009). Using the Lesson Study Approach to Plan for Student Learning. Middle School Journal, 40(3), 50-57. https://doi.org/10.1080/00940771.2009.11495587

Lewis, C., \& Hurd, J. (2011). Lesson Study step by step. How Teacher Learning Communities Improve Instruction. Portsmouth, NH, USA.

Lewis, C., Perry, R., \& Hurd, J. (2004). A deeper look at lesson study. Educational Leadership, 61(5), 18-23.

Mavrogiorgos, G. (2008). The Educational Unit as an Institution for the Formation and Exercise of Educational Policy. In: A. Athanasoula-Reppa, A. Dakopoulou, M. Koutouzis, G. Mavrogiorgos, \& D. Halkiotis. Management of Educational Units: Educational Management and Politics. v. A, 119-163. Patras: OR.

Meyer, R. (2005). Lesson Study: The effects on teachers and students in urban middle schools. Dissertation, Bylor University.

Mynott, J. (2017). A primary head teacher's exploration of lesson study. (Doctoral Dissertation). University of Hertfordshire, UK. Retrieved from:

https://uhra.herts.ac.uk/bitstream/handle/2299/18330/14107916\%20Mynott\%20John\%20Final\%20Submission.pdf ?sequence $=1$

Oliva, P. (1993). Supervision in Today's Schools. New York: Logmann.

Panoutsos, C. (2015). Collaborative course design (Lesson study): The case of the ratios and proportions. Available at: http://nemertes.lis.upatras.gr/jspui/bitstream/10889/8637/1/\%CE\%94\%CE\%B9\%CF\%80\%CE\%BB\%CF\%89\%CE

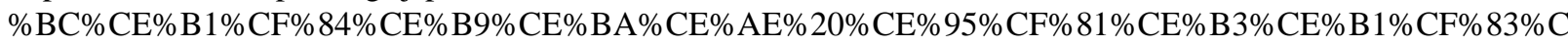
Е\%AF\%CE\%B1\%20\%CE\%A0\%CE\%B1\%CE\%BD\%CE\%BF\%CF\%8D\%CF\%84\%CF\%83\%CE\%BF\%CF\%85 $\% 20 \% \mathrm{CE} \% \mathrm{~A} 7 \% \mathrm{CF} \% 81 \% \mathrm{CE} \% \mathrm{AE} \% \mathrm{CF} \% 83 \% \mathrm{CF} \% 84 \% \mathrm{CE} \% \mathrm{BF} \% \mathrm{CF} \% 85 . \mathrm{pdf}$

Papakonstantinou, G. (2008). Introduction of innovations in the educational unit: the role of the director. In: Training Guide: Intercultural Education and Action, 231- 240. Thessaloniki, AUTh.

Polemi-Todoulou, M. (2010). The Systemic Approach-Key to a New Educational Planning. Metologist, Systemic Society of Northern Greece, 18, 1-27. 
Raymond, D., Butt, R., \& Townsend, D. (1993). Frameworks for teacher development: Reflections from teacher stories. In: Hargreaves, A., \& Fullan, M. The evolution of teachers. Transl.: P. Chatzipantelis. Athens: Pataki.

Rekalidou, G. (2012). Improving teaching. The case of Lesson Study. Pedagogy-Theory and Practice, 5, 98-109.

Rekalidou, G., Karadimitriou, K., \& Moumoulidou, M. (2013). Basic components of the implementation of the Lesson Study model in the practical training of four-year students of TEEP-DTU: collaboration, reflection, feedback, observation. Conference of the Network of Practice Exercises in the Department of Early Childhood Education, on "Improving the Education of Future Teachers in Crisis of Institutions: Proposals, Applications". Alexandroupolis, 26-28 September.

Robson, C. (2010). Real-world research. Transl.: V. Dalakou, \& K. Vassilikou. Edited by: K. Michalopoulou, \& F. Kalyva. Athens: Gutenberg.

Rock, C., \& Wilson, C. (2005). Improving teaching through lesson study. Teacher Education Quarterly, 32 (1), 77-92

Shaun, A. (2014). Perfect CPD Teacher-Led. U.K.: Independent Thinking Press.

Sirotic, N. (2015). Knowledge Growth through Lesson Study: A Case of Secondary Mathematics Teachers' Collaborative Learning. (Doctoral Dissertation). Simon Fraser University, Canada. Retrieved from: http://www.peterliljedahl.com/wp-content/uploads/Thesis-Natasa-Sirotic.pdf

Stepanek, J., Appel, G., Leong, M., Turner, M. M., \& Mitchell, M. (2007). Leading Lesson Study. A practical guide for teachers and facilitators. California, USA.

Syvaka, T., \& Ginoudi, A. (2014). The role of the school manager in intercultural collaborations - through case study. Curriculum, Educational-Scientific Review, 2, 153-162.

Thiessen, D. (1993). Teacher development based on the classroom. In: Hargreaves, A., \& Fullan, M. The evolution of teachers. Transl.: P. Chatzipantelis. Athens: Pataki.

Thompson, D. (2015). An analysis of the perceived impact of lesson study on improving secondary school STEM teacher effectiveness. (Doctoral Dissertation). University of Central Florida, FL, USA. Retrieved from http://stars.library.ucf.edu/cgi/viewcontent.cgi?article=2310\&context=etd

Van Sickle, J. (2011). Lesson Study's impacts on teacher perception of efficacy in teaching. A Thesis of Humboldt State University.

Verhoef, N., \& Tall, D. (2011). Lesson Study: The effect on teachers' professional development. Proceedings of the 35th Conference of the International Group for the Psychology of Mathematics Education, 1, XXX-YYY. Ankara,

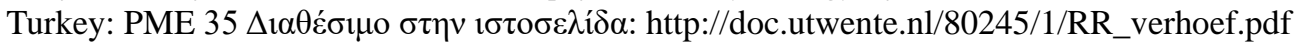

Yakoumi, S., \& Theofilidis, C. (2012). The collaborative culture as a supportive tool in the work of teachers. 12th Conference of the Pedagogical Society of Cyprus. Available at:

http://www.pek.org.cy/Proceedings_2012/papers/sygxrona_themata/Giakoumi\&Theofilides.pdf

\section{Copyrights}

Copyright for this article is retained by the author(s), with first publication rights granted to the journal.

This is an open-access article distributed under the terms and conditions of the Creative Commons Attribution license which permits unrestricted use, distribution, and reproduction in any medium, provided the original work is properly cited. 